\title{
Nordic Dual Income Taxation of Entrepreneurs
}

\author{
Vesa Kanniainen \\ University of Helsinki, HECER and CESifo \\ and \\ Seppo Kari \\ Government Institute for Economic Research \\ and \\ Jouko Ylä-Liedenpohja \\ University of Tampere and CESifo
}

Discussion Paper No. 156

April 2007

ISSN 1795-0562

HECER - Helsinki Center of Economic Research, P.O. Box 17 (Arkadiankatu 7), FI-00014 University of Helsinki, FINLAND, Tel +358-9-191-28780, Fax +358-9-191-28781, E-mail info-hecer@helsinki.fi, Internet www.hecer.fi 


\title{
Nordic Dual Income Taxation of Entrepreneurs *
}

\begin{abstract}
The paper shows how entrepreneurial taxes interact with the career choice of individuals, the quality of entrepreneurs, and their investment behavior. It is particularly relevant to differentiate the early effects on start-up enterprises with substantial uncertainty from the tax effects on mature firms where the uncertainty is resolved. Conditions are derived for the Nordic dual income tax to be neutral and they are found to be stringent. Profit expectations matter. The Nordic dual encourages (discourages) the establishment of new enterprises by entrepreneurs who anticipate high (low) profitability.
\end{abstract}

JEL Classification: H25

Keywords: dual income taxation, enterprise taxes

\author{
Vesa Kanniainen \\ Department of Economics \\ University of Helsinki \\ P.O.Box 17 \\ FI-00014 University of Helsinki \\ FINLAND \\ Jouko Ylä-Liedenpohja \\ Department of Economics and Accounting \\ University of Tampere \\ FI-33014 University of Tampere, \\ FINLAND \\ e-mail: jouko.yla-liedenpohja@uta.fi
}

Seppo Kari

Government Institute for Economic Research

P.O. Box 1279

FI-00101 Helsinki

FINLAND

e-mail: vesa.kanniainen@helsinki.fi e-mail: $\underline{\text { seppo.kari@vatt.fi }}$

* This is a revision of the paper presented at the CESifo 2006 Public Economics workshop, the 2006 EEA congress in Vienna and the 2006 IIPF congress in Cyprus. The authors are grateful to conference participants, three anonymous referees and the editor for their valuable comments on the earlier draft. Vesa Kanniainen gratefully acknowledges the financial support of the Yrjö Jahnsson Foundation and Jouko Ylä-Liedenpohja that of the Nordic Tax Research Council and the OP Bank Group Research Foundation. 


\section{Introduction}

The idea of taxing capital and labor income differently has received substantially attention over several years (Sødersen 2005a, 2005b; Lindhe-Södersten-Öberg, $2002,2004)$. The theoretical foundations for such a proposition from the point of view of optimal tax theory have been explored by Sødersen (2005b) in particular. One of them is the change of the world economy towards internationally more mobile capital. The income of entrepreneurs represents partly return on capital invested and partly compensation for their entrepreneurial effort and ability. Hence, entrepreneurial income is the natural subject of a mixed tax treatment. In the development of such an approach, the Nordic countries were pioneers. In the early 1990s Finland, Sweden and Norway replaced their global income taxation, where all economic income is subject to a single progressive tax schedule, by a version of dual income taxation. The personal income of an entrepreneur was divided into capital income and earned income. Only the latter is taxed at a progressive schedule while the former is taxed at a flat rate. Hence, it was necessary to solve difficult problems of finding an appropriate splitting procedure. The solutions for this problem were not coordinated. Instead, somewhat different experiments were undertaken. ${ }^{1}$

The Nordic reforms were designed to produce efficiency gains by reducing the distortion caused by the non-uniform treatment of different kinds of income from capital in the old system and to adopt, instead, a clear-cut dual income tax (Nielsen and Sørensen 1997 and Sørensen 2005b). Also Tikka (1993) saw the Nordic dual as a small country response to increasing international capital mobility. Subsequently, Sørensen (1994) suggested that dual income tax may

\footnotetext{
${ }^{1}$ The Nordic dual with its split rules has attracted wide interest, reflected also in the recent DICE Report of CESifo (DICE 2004). In the German popular debate, the dual tax has been seen as a practical solution to tax competion from economies in transition. Indeed, the most recent contribution appears to be the detailed proposal for a comprehensive tax reform by the German Council of Economic Experts (2006). A proposal for a Swiss reform has been worked by Keuschnigg and Dietz (2005).
} 
cause fewer distortions than the conventional income tax. Nielsen and Sørensen (1997) argued that the latter has a distortionary bias against investment in non-human capital, which can be offset in the dual taxation. Sørensen (2005a, 2005b) elaborates a new split rule that delivers neutrality of investment and financing decisions of entrepreneurs.

The major novelty of the Nordic dual appears in its acknowledgement that the taxation of the entrepreneurial income should differentiate the income from capital and labor effort. Split rules were introduced, defining the maximum that is viewed as capital income for tax purposes. The practical solution revolved around finding a measure of assets invested (capital base) and an appropriate rate of return on those assets (to be called a presumptive rate of return).$^{2}$ The approach has been found appropriate whether the unincorporated entrepreneur operates as self-employed or an employer as a sole proprietor, is part of a partnership or runs a closely-held corporation (CHC). The income of those entrepreneurs is viewed as personal income and it is not subject to a separate profits tax. ${ }^{3}$ The splitting approach thus applies to the income (profit) of the unincorporated entrepreneurs. It also applies to the dividends from incorporated closely-held companies ${ }^{4}$. Otherwise, the taxation principles of widely-held (e.g. listed) companies apply to the CHS's. The dividends and realized capital gains from them are always treated as income from capital. Prior to the personal tax, profits from incorporated businesses are taxed at the corporation tax rate.

The idea of a dual income tax can be built into the tax system in various

\footnotetext{
${ }^{2}$ A separate proportional tax on all types of capital income has been another feature of the solution. The benefits of the latter choice have been recognized in the Johansson-Samuelson theorem, explicated by Sinn (1987), saying that a uniform tax on all capital income, net of true economic depreciation, is neutral in respect of the choice of investment projects.

${ }^{3}$ Note that also the workers' return on saving is taxed as capital income, not as earned income. Uniformity requires the the same principle applies to enterpreneurs.

${ }^{4}$ The motive for the dividend split in the case of CHSs is different from that on unincorporated entrepreneurs, i.e. to prevent tax arbitrage. This is the Swedish and Finnish approach. Up to 2005, Norway split the income of a CHC at the firm level. In the most recent reform, also Norway has moved to split the dividends.
} 
ways. In the recent Keuschnigg and Dietz (2005) tax proposal, the income tax is dual in the sense that the taxation of capital income is based on a relatively low tax rate while the taxation of earned income is progressive with the highest marginal tax rates exceeding the proportional tax rate on capital income. This is in line with the Nordic dual income tax. The entrepreneurs' income, however, is not split. The double tax on equity returns is mitigated by the introduction of the ACE allowance. When it comes to tax the rent, the top marginal tax rate on equity returns is aligned to the top marginal tax rate on earned income. The purpose of the latter feature is to alleviate the income shifting incentive.

There are a few earlier studies on the behavior of enterprises under the dual income tax. Hagen and Sørensen (1998) discussed at length the division of income from small businesses. Kari (1999) argued that, depending on how the ceiling of imputed capital income is determined, the Finnish dual income tax may lead to a strong investment incentive for closely-held companies. Lindhe et al. (2002, 2004) showed that the Swedish splitting scheme, based on the acquisition value of company shares, is neutral in its treatment of investments by a closely-held company $(\mathrm{CHC})$ financed by retained earnings in respect of those by a widely-held one. The Norwegian scheme was found to be distortive. Alstadsaeter (2003) considered the Norwegian case, suggesting that it provides entrepreneurs with great incentives to participate in tax-minimizing income shifting. She also concluded that the Norwegian dual income tax leads to overinvestment and that the corporate organizational form serves as a tax shelter for high-income entrepreneurs. Hagen and Sørensen (1998), Panteghini (2001) and Sørensen (2005a) address the important issue of whether the presumptive rate of return should, in addition to a default-free rate of interest, include a risk premium. Fjaerli and Lund (2001) report that the choice of the type of payout from the CHCs to their owners is strongly, but not uniquely, 
motivated by taxes.

Though several papers have discussed enterprise taxation, we undertake our tax analysis in a different model. We develop a model of an entrepreneur whose decisions include the entry at the start-up stage enterprise subject to an entry cost (initial effort needed), the failure risk, the expansion investment of the surviving enterprises and the withdrawal of the founding entrepreneur at the mature state, when he can give up his "baby". Most important, our framework for an owner-managed enterprise is able to adopt the role of risk-taking of an entrepreneur. $^{5}$

We ask under what conditions the Nordic approach satisfies the neutrality criterion in respect of the entrepreneurial choices. Is the Nordic approach a reasonable strategy to tax entrepreneurs? This is our research question. Moreover, we ask what effects it exerts on the start-up stage and expansion stage cost of capital and whether it interferes the occupational choice of potential entrepreneurs.

In our analysis, the wage rate and market interest rate are given. These assumptions are consistent with the idea of enterprises being hosted by a small open economy with the wage rate being determined by productivity in the tradeables sector and with the residence principle applied for the taxation of worldwide interest income. The start-up is assumed to be domestically owned and we focus on start-ups financed by the entrepreneur's own funds. Therefore the domestic taxes on dividends and capital gains remain relevant.

Our findings include some general results and some related to the Nordic dual in particular. The neutrality results of dividend taxation from the tax theory of mature companies do not carry over to start-ups. Theory of the cost of capital for investments has centered on the issue of whether double taxation of dividends

\footnotetext{
${ }^{5}$ The insurance function of income taxation does not apply in the case of start-up enterprises. The government does not share losses from the start-up phase and no insurance is available for the genuine business risk because of moral hazard.
} 
matters for marginal investments or whether it is that of retained earnings, the dividend tax falling upon inframarginal investments. ${ }^{6}$ We show that it is indispensable to differentiate the early tax effects on start-up enterprises from the tax effects on mature firms. One lesson from our research is that double taxation of dividends can raise the total tax rate on entrepreneurial income above that on earned income, making dividend tax to act as an entry barrier. Though rather evident, this proposition has not been stated clearly. Another reason for a high start-up cost of capital is uncertainty which is shaded more or less away in the case of mature companies. These results are not constrained to the Nordic dual.

In our analysis of the Nordic dual some clear-cut rules are derived for tax neutrality in the investment choice of the sole proprietors; in the case of incorporated enterprises, the conditions are harder to implement in practise. If a non-neutral dual is chosen in practise, we show that heterogenous expectations of profitability generate a distribution for the cost of capital among entrepreneurs because of a different marginal tax rate on highly profitable enterprises from less profitable enterprises. For an incorporated enterprise, we find that the entrepreneur's ability threshold rises with the tax rate even when there is a tax structure with uniform tax rates. In particular, Nordic dual encourages (discourages) the establishment of a new enterprise by an entrepreneur who expects high (low) profitability. The low types face a higher cost of capital for start-up and expansion investments. For enterprises with high expected profitability, the Nordic dual rules may give a boost to expansion investment and mitigate the penalty on start-up investment caused by taxing dividends as earned income.

The structure of the paper is as follows. Section 2 develops the components of the model without taxation. Section 3 introduces the Nordic dual rules for

\footnotetext{
${ }^{6}$ The two views are summarized by Auerbach (1983). The "new view" was developed independently by King (1974), Bergstöm and Södersten (1977), Auerbach (1979) and Bradford (1981).
} 
the taxation of sole proprietors and section 4 for the taxation of incorporated enterprises, investment incentives being analyzed in section 5. Section 6 studies the career choice between an entrepreneur and a laborer. Section 7 concludes.

\section{Model of an Entrepreneur}

Entrepreneurial qualities Consider a single entrepreneur entering a particular industry, determined by his skill. Even though there can be differences in the prospects for returns in different industries, entrepreneurs are unable to switch since their skills are industry-specific. The expectations of profitability can also vary across entrepreneurs.

Potential entrepreneurs have a unique ability to produce project ideas. Some are more productive and innovative than others. There is a continuum of them, indexed by ability $a \in(0, \bar{a})$. There are three stages, indexed by time, $t=0,1,2$. In stage $t=0$, individuals face a career choice between forming an enterprise and entering the labor market. Commitment to entrepreneurship requires an initial effort, $e>0$, and an initial investment, $k>0$, at time $t=0$. Effort represents a non-replicable input and the effort cost is convex, $c(e)=\frac{1}{2} e^{2}$. Entrepreneurs do not know ex ante the true profitability $\theta$ of their idea, only its distribution. The first production stage provides entrepreneurs with a signal, $\theta$, of the profitability. Investment in a first-stage project thus provides a risky return

$$
R(e, k, \theta)=k+a f(e, k ; \theta)
$$

Our notation here is non-standard but useful in showing that a successful entrepreneur gets back his initial investment $k$ and an incremental return $a f\left(e, k ; \theta^{i}\right)$. The signal can take three values, $\theta^{\circ}<\theta^{L}<\theta^{H}$. With the probabilities $\pi^{L}, \pi^{H}$, the project will be a success, the initial investment being recovered and an op- 
erating profit made with $a f\left(e, k ; \theta^{H}\right)>a f\left(e, k ; \theta^{L}\right)>0$. We assume $f$ to be jointly concave in $e$ and $k$. Success occurs with the probability $\pi^{L}+\pi^{H}<1$. Failure occurs with the probability $1-\Sigma \pi^{i}$, when the project is of the type $\theta=\theta^{\circ}$, and returns nil. Enterprises with a bad signal $\theta^{\circ}$ leave the market. Those with a good signal have the option to allocate the first-stage cash flow to an immediate dividend, $d$, or to expansion investment $K>0$ at time $t=1$. If only to clarify, the decisions on career choice, effort $(e)$, initial investment $(k)$ and first production are undertaken in period 0. After the signal has arrived, the expansion investment $K$ and dividend $(d)$ are decided in period 1 .

To highlight the idea that risks are greatest at the early stage of a project, we assume that the second-stage return is not subject to uncertainty. The enterprise or its capital is assumed to be sold at its net asset value at time $t=2$.

To emphasize the fundamental differences between start-up enterprises and mature companies, we introduce different technologies in the two stages, af $(e, k ; \theta)$, $F(K ; \theta)$. The second-stage technology can be viewed as an advanced version of the first-stage technology, formally expressed as $F(a, x ; \theta)=a f(0, x ; \theta)$. It does not require specialized inputs. Hence, no effort is needed and the return is given by $F(a, K ; \theta)$ which, given $\theta$, is increasing and strictly concave in $a$ and $K$. If only to economize, we suppress $a$ and work with $F(K ; \theta){ }^{7}$ The second-stage return is greater for an $H$-firm than for an $L$-firm, i.e. $F\left(K ; \theta^{H}\right)>F\left(K ; \theta^{L}\right)$.

We assume that the first-stage capital $k$ depreciates fully while the secondstage capital does not. This distinction also highlights the heterogeneity of capital over the life-cycle of the enterprise. In the second production stage the

\footnotetext{
${ }^{7}$ Note, however, that a represents a unique ability, imbedded in the personality of the entrepreneur, to create cash flows. Intuitively, as the start-up technology is a prototype of the mature company, the difference arises from learning and business experience. To survive successfully into an expansion stage, it is also necessary for the entrepreneur to develop a proper organizational set-up for his business, a well functioning entrepreneurial or corporate culture. In a merger, the acquiring firm loses the unique ability of the entrepreneur unless his ability is imbedded in the corporate culture.
} 
successful enterprise accumulates net assets, $\Delta V=F\left(K ; \theta^{i}\right)+K$.

The value of an entrepreneurial career Assume risk neutrality and let $V$ denote the value of an entrepreneurial career in a risky industry. The cash flows in periods 1 and 2 are

$$
d=a f(e, k ; \theta)+k-K ; \quad D=F(K ; \theta)+K .
$$

Let $r=$ the interest (discounting) rate. The second-stage cash flow $D$ is conditional on success in the initial stage, but deterministic for any successful project. In terms of backward induction, the project value at the beginning of the second stage is

$$
V_{1}(K ; \theta)=-K+\frac{D}{1+r}
$$

Then, the optimal risky career satisfies

$$
V_{0}^{*}(a, \theta)=\max _{e, k}\left(-(c(e)+k)+\Sigma_{i} \pi^{i} \frac{1}{1+r}\left[a f(e, k ; \theta)+k+V_{1}^{*}(\theta)\right]\right),
$$

where $V_{1}^{*}(\theta)=\max _{K} V_{1}(K ; \theta)$, provided that the participation constraint (7) below is satisfied. The first-order conditions for the maximization of (3) are

$$
\begin{gathered}
F_{K}\left(K ; \theta^{i}\right)=r ; \quad i=H, L \\
\Sigma_{i} \pi^{i} f_{k}\left(e, k ; \theta^{i}\right)=\left(\frac{1}{a}\right)\left(r+1-\Sigma_{i} \pi^{i}\right) \\
\Sigma_{i} \pi^{i} f_{e}\left(e, k ; \theta^{i}\right)=\left(\frac{e}{a}\right)[1+r] .
\end{gathered}
$$

The cost of capital for expansion investment of surviving enterprises is given by (4), the rate of interest. The enterprise of the more profitable entrepreneur has a greater growth, $K^{H}>K^{L}$. The first-stage cost of capital is (5) and 
accommodates the risk effect. The probability of success $\Sigma \pi^{i}$ raises the expected return (left-hand side) and the probability of failure $1-\Sigma_{i} \pi^{i}$ increases the cost of capital (right-hand side). The latter is the skill-scaled asset cost, $1 / a$, multiplied by the full opportunity cost of funds employed. High failure risk $\left(1-\Sigma \pi^{i}\right)$ thus raises the initial cost of capital, discouraging early investment. More able entrepreneurs invest more initially. Note that when the two conditions (4) and (5) hold with equality, they describe an interior solution for optimal dividend along the growth path. ${ }^{8}$ Condition (6), with $c(e)=\frac{1}{2} e^{2}$, gives optimal effort. The left-hand side represents the marginal expected return on effort. The righthand side is the forward value of the skill-scaled marginal cost of effort. A high first-stage cost of capital also reduces effort.

The concept of the entry threshold in terms of the marginal entrepreneurial $a^{m}$ ability completes our basic framework. At the outset, entrepreneurs do not know the true type of their project, $\theta$, only its distribution. They compare various candidate projects using the discount rate, $r$, to provide a ranking. Those who enter as entrepreneurs evaluate the expected value of their career, $V$, and compare it to the life-time value of an outside option, $w$, labor income, insured by social insurance. Then, the entry threshold is given by

$$
V_{0}^{*}(a) \geq w
$$

Evaluating, $\partial V_{0}^{*}(a) / \partial a=\frac{\pi}{1+r} f(\widehat{e}, \widehat{k}, \theta)>0$ holds because by the envelope theorem we need to consider only the direct effect of a parameter change on the optimized function (3). The project value is proportionately increasing in entrepreneurial ability. The most able agents become entrepreneurs, given that the outside option is unrelated to the entrepreneurial skill. For the marginal

\footnotetext{
${ }^{8}$ We can also have a corner solution with all cash flow invested and no dividends paid out if the second-stage investment is expected to be highly profitable with $F_{K}(\widehat{K})>r$. Excluding the possibility of a negative dividend (share issue), the cost of capital does not determine the amount invested. In this paper, we do not analyze corner solutions in depth.
} 
entrepreneur with ability $a^{m}, V_{0}^{*}\left(a^{m}\right)=w$ holds.

\section{Tax Effects on Sole Proprietors and Partner- ships}

In the case of a sole proprietor or a partnership member, there is no dividend income for tax purposes. Without a split approach, the business income of a sole proprietor or a partnership member is taxed at the rate on earned income, $\tau_{w}$. This is the tax rate determined by the realized total business income in the respective income band $i$ on the progressive rate schedule, but we assume it to take only two values $\tau_{w}^{L}<\tau_{p}<\tau_{w}^{H}$ where $\tau_{p}$ is the tax rate on interest income. For profitable enterprises, it holds $\tau_{p}<\tau_{w}^{H}$. However, we do not want to exclude the possibility that for low-income entrepreneurs it may be that $\tau_{w}^{L}<\tau_{p} \cdot{ }^{9}$

In the Nordic dual, the entrepreneur's business income is split in order to tax part of it as capital income. The basic principles of unincorporated enterprises are the same in all Nordic countries. Our question is when a split approach is neutral with respect to the early-stage and later-stage cost of capital. Then, we ask whether the Nordic system deviates from the neutrality benchmark. In the case of a sole proprietor or a partnership, retained profit once taxed is not subject of another tax at exit when the business is sold out at its net asset value in the final stage.

Consider first taxation without the split. Denoting the tax rate on interest income by $\tau_{p}$, the net rate of interest is given by $r=\left(1-\tau_{p}\right) \widetilde{r}$, with $\widetilde{r}$ denoting the gross interest rate. Under success, the tax liability is thus

$$
T(e, k, K ; a, \theta)=T_{1}+T_{2}=\tau_{w} \frac{a f(e, k ; \theta)}{1+r}+\tau_{w}^{i} \frac{F(K ; \theta)}{(1+r)^{2}} .
$$

\footnotetext{
${ }^{9}$ Actually, this holds in the Finnish case.
} 
The sole proprietor maximizes

$$
V^{\tau}(\theta)=\max _{e, k, K}\left[V_{o}(e, k, K ; a, \theta)-\Sigma_{i} \pi^{i} T(e, k, K ; a, \theta)\right]
$$

where $V_{o}(\cdot)$ is given by $(3)$. The first-order conditions of this optimization problem are

$$
\begin{gathered}
F_{K}\left(K ; \theta^{i}\right)=\frac{r}{1-\tau_{w}^{i}} ; \quad i=H, L \\
\Sigma_{i} \pi^{i}\left(1-\tau_{w}^{i}\right) f_{k}\left(e, k ; \theta^{i}\right)=\left(\frac{1}{a}\right)\left(r+1-\Sigma_{i} \pi^{i}\right) \\
\Sigma_{i} \pi^{i}\left(1-\tau_{w}^{i}\right) f_{e}\left(e, k ; \theta^{i}\right)=\left(\frac{e}{a}\right)[1+r] .
\end{gathered}
$$

We notice that these conditions are also the benchmark values of a JohanssonSamuelson (JS) tax, taxing all income comprehensively once, including interest income, i.e. $\tau_{w}=\tau_{p} \cdot{ }^{10}$ Thus while the cost of capital for expansion investment is the gross rate of interest $\widetilde{r}$, the JS tax clearly is not neutral in respect of the first-stage investment subject to a prospective capital loss of $\left(1-\Sigma \pi^{i}\right)$ because such a loss is not deductible from taxable income. In contrast to the DomarMusgrave (1944) case and for a given $\tau_{w}$, the tax-adjusted return which the entrepreneur must earn is $1 /\left(1-\tau_{w}\right)>1$ times the expected unrecoverable initial stake.

Expansion Investment: When Does the Split Lead to Neutrality? The Nordic dual splits the entrepreneur's total business income into income from capital and earned income using the concept of a capital base. ${ }^{11}$ This consists

\footnotetext{
${ }^{10}$ The so called Johansson-Samuelson tax, as phrased by Sinn (1987), refers to a uniform tax on all capital income with economi depreciation.

${ }^{11}$ There are differences in many details in the dual income systems of the three Nordic countries which have adopted it. In the taxation of unincorporated business, the various Nordic approaches are quite similar. In the case of corporations, Sweden and Finland split the dividend while Norway used to split the pre-tax profit (before its most recent reform). Moreover, Finland defines the capital base as including the financial assets while Norway does not. In addition, Sweden does not make the expansion investment qualify for the capital base while Finland does. For discussion of some of these details, we refer to our CESifo discussion
} 
of the entrepreneur's initial investment and the reinvested business income, to be denoted by $B_{1}$ and $B_{2}$ in the two stages. The tax authorities impute the amount of capital income by a presumptive rate of return, say $\rho$, and taxes $\rho B_{1}$ and $\rho B_{2}$ at the flat rate, $\tau_{p}$. Any remaining business profits are taxed at the rate of earned income, $\tau_{w}^{i} \cdot{ }^{12}$

The after-tax value of the entrepreneurial career in the second stage is then

$$
V_{1}^{*}\left(\theta^{i}\right)=-K+\frac{F(K)+K-\left[\tau_{p} \rho B_{2}+\tau_{w}^{i}\left(F(K)-\rho B_{2}\right)\right]}{1+r} .
$$

Solving for the optimal expansion investment $K$,

$$
F_{K}=\left(\frac{1-\tau_{p}}{1-\tau_{w}^{i}}\right) \widetilde{r}-\left(\frac{\tau_{w}^{i}-\tau_{p}}{1-\tau_{w}^{i}}\right) \rho B_{2}^{\prime}(K)
$$

Require now in the tax system with $\tau_{w}^{i}$ different from $\tau_{p}$ that the pre-tax cost of capital equals that in the tax-free economy, the gross interest rate $F_{K}=\widetilde{r}{ }^{13}$ we obtain for the neutrality condition,

$$
\rho B_{2}^{\prime}(K)=\widetilde{r}
$$

We thus have proved

Proposition 1 For tax neutrality in respect to growth of the enterprises of selfemployed and partnerships enterprises, the marginal tax shield produced by the split system should satisfy $\rho B_{2}^{\prime}(K)=\widetilde{r}$.

The legislator has therefore alternatives. It can introduce either a high presumptive rate $\rho$ and low marginal base $B_{2}^{\prime}(K)$ or the other way round. The paper version, Kanniainen, Kari and Ylä-Liedenpohja (2005).

${ }^{12}$ Some authors prefer the terms normal dividend and excess dividends... " Jouko kirjoittaa lyhyen alaviitan.

${ }^{13}$ Note that the gross interest rate $\widetilde{r}$ is the same in the tax-free and in the taxed economy as we have assumed the case of a small open economy. 
Nordic dual can be interpreted to be based on the idea that $B_{2}=K$. Hence $B_{2}^{\prime}(K)=1$. Neutrality of the Nordic dual thus requires that $\rho=\widetilde{r}$, i.e. that the presumptive rate equals the gross interest rate.

Investment Incentive in the Growth Stage If the legislator has ended up in a non-neutral taxation of entrepreneurs, we report a powerful result.

Proposition 2 For those entrepreneurs whose realized profit was low $\pi^{H}<\pi^{L}$ with $\tau_{w}^{L}<\tau_{p}$, the split system represents a penalty on expansion investment. For those enterprises which turned out to be highly profitable, the split system provides a strong investment incentive in the expansion stage.

Proof. The conclusion can be obtained from the sign of the latter term including $\left(\frac{\tau_{w}-\tau_{p}}{1-\tau_{w}}\right)$ in the above first-order condition (14).

Uncertainty about $\theta$ is revealed before the expansion investment so that the tax relief is available for those entrepreneurs who expect their total business income to settle in the income band where they face a tax rate $\tau_{w}^{H}>\tau_{p}$. But, if the business generates relatively little total income so that $\tau_{w}^{L}<\tau_{p}$ holds in that income band, the Nordic split rule alters into an additional tax on the entrepreneur's expansion-stage capital, leading to a higher cost of capital than without the dual. ${ }^{14}$

In deriving the above result, we have considered the tax rate structure as given. When a split system is introduced in an equilibrium where investment behavior is distorted by the existing tax system, the Nordic dual appears to provide a second-best improvement. Entrepreneurs with profitable ideas find that the tax on retained profit is reduced, making an expansion investment worthwhile at the margin.

\footnotetext{
${ }^{14}$ This is the reason why the current system of Finland allows an unincorporated entrepreneur to elect the presumptive rate $\rho$ to be set at either 20 per cent or 10 per cent.
} 
Initial Investment The expected first-stage tax liability is

$$
T_{1}=\tau_{p} \rho B_{1}+\Sigma_{i} \pi^{i} \tau_{w}^{i}\left(a f(e, k, \theta)-\rho B_{1}\right)
$$

Inserting this into the value function, the first-order condition in respect of the initial investment is

$$
\left.\Sigma_{i} \pi^{i}\left[\left(1-\tau_{w}^{i}\right) a f_{k}^{\prime}(e, k ; \theta)\right]=\widetilde{r}\left(1-\tau_{p}\right)+1-\Sigma_{i} \pi^{i}-\Sigma_{i} \pi^{i}\left(\tau_{w}^{i}-\tau_{p}\right) \rho B_{1}^{\prime}(k)\right)
$$

We contrast this to the comparable condition in a tax-free economy

$$
\Sigma_{i} \pi_{i} a f_{k}^{\prime}(e, k ; \theta)=\widetilde{r}+1-\Sigma_{i} \pi^{i}
$$

Solving for $\rho B_{1}^{\prime}(k)$ which maintains the investment equal to that in a tax-free economy,

$$
\rho B_{1}^{\prime}(k)=\frac{\Sigma_{i} \pi_{i} \tau_{w}^{i} a f_{k}^{\prime}\left(e, k ; \theta^{i}\right)-\widetilde{r} \tau_{p}}{\Sigma_{i} \pi^{i}\left(\tau_{w}^{i}-\tau_{p}\right)} .
$$

To satisfy neutrality in the case of uncertainty about the success and the industry prospects, the marginal capital base $\rho B_{1}^{\prime}(k)$ ought to be industry- or even enterprise specific as it depends on profit expectations and their probabilities. Moreover, it depends on the existing tax rates, $\tau_{w}^{i}, \tau_{p}$. Such a challenging outcome may be a relevant requirement in the real world but it is an unrealistic one. However, it is useful to consider the neutrality when only the risk of failure is involved.

Failure Risk and the Neutrality Condition Let us thus give up for a moment the distinction between high-profitable and low-profitable enterprises. Assume that all entrepreneurs face the risk of failure $(1-\pi)$ but in case of success (with probability $\pi$ ) have the same profitability. The above condition 
simplifies to

$$
\rho B_{1}^{\prime}(k)=\frac{\pi \tau_{w} a f_{k}^{\prime}(e, k ; \theta)-\widetilde{r} \tau_{p}}{\pi\left(\tau_{w}-\tau_{p}\right)} .
$$

In a tax-free economy, $\pi a f_{k}^{\prime}(e, k ; \theta)=\widetilde{r}+1-\pi$. Inserting, we obtain the neutrality condition

Proposition 3 In the presence of a failure risk, the neutrality condition for the Nordic dual with respect to the early investment is

$$
\rho B_{1}^{\prime}(k)=\frac{\widetilde{r}}{\pi}+\left(\frac{\tau_{w}}{\tau_{w}-\tau_{p}}\right) \frac{1-\pi}{\pi} .
$$

This gives the split rule which yields the same first-period investment. We can interpret the Nordic approach such that the early stage capital base equals the capital invested, $B_{1}(k)=k$. Then, the presumptive rate $\rho$ should not only be related to the risk-adjusted interest rate $\frac{\widetilde{r}}{\pi}$ but also to the tax structure. This creates some tedious practical problems. In practice, the Nordic countries have chosen to adjust the presumptive rate $\rho$ for, say an average (economy-wide) risk premium. This is "on average" a good way to go though inter-firm differences in risks somewhat distort the outcome.

Considering our Propositions 1 and 3 together, the government faces a tradeoff. If the presumptive tax rate is chosen to satisfy the neutrality of investment in the expansion stage, $\rho=\widetilde{r}$, this may clearly discourage the early (riskier) investment. On the other, if the risk adjustment is carried out to achieve neutrality in the early investment, mature firms may overinvest. ${ }^{15}$

Actual Investment Incentives How does the actual non-neutral split rule affect the behavioral incentives? We obtain

Proposition 4 For those entrepreneurs who expect to face a tax rate $\tau_{w}^{L}<\tau_{p}$,

\footnotetext{
${ }^{15} \mathrm{We}$ are grateful to a referee for pointing out this implication.
} 
the split system represents a penalty on start-up investment and effort, magnifying the risk of failure effect. However, for those enterprises which expect to face a tax rate $\tau_{w}^{H}>\tau_{p}$, the split system provides a strong investment incentive in the early stage.

Proof. The result derived from the first-order condition (16) above.

In their influential proposition, De Meza and Webb (1999) have suggested that a tax on new enterprises results in a welfare gain. This policy proposition is derived in a model where firms resort to outside financing in conditions of asymmetric information. Our result concerning the tax penalty in a non-neutral dual system on new enterprises with low expected profitability appears to represents a tax on enterprises with a positive but low values, see also our last chapter.

\section{Dual Taxation of Closely-Held Incorporated Enterprises}

In the case of sole proprietors and partnerships, the Nordic countries have adopted an approach where it is the business income which is subject to the split while in the case of closely held corporation, it is the dividend. This holds also for Norway after the most recent tax reform.

Our modelling can be interpreted to capture both the classical and the imputations systems, regarding an incorporated company and its owners as separate tax entities. One can think that the imputation systems are reflected in the magnitude of our tax rates $\tau_{d}$ and $\tau_{w}$. Such an interpretation simplifies the notation.

Let $\tau_{c}, \tau_{d}, \tau_{w}$ denote the tax rates on profits, dividends and earned income. Write first the expression for the present value of the integrated tax liability of 
a successful $\mathrm{CHC}$ without the split rule

$$
\begin{aligned}
T(e, k, K, \theta) & =\tau_{c} \frac{a f(e, k, \theta)}{1+r}+\tau_{d} \frac{\left(1-\tau_{c}\right) a f(e, k, \theta)+k-K}{1+r} \\
& +\tau_{c} \frac{F(K, \theta)}{(1+r)^{2}}+\tau_{d} \frac{\left[F(K, \theta)\left(1-\tau_{c}\right)+K\right]-k}{(1+r)^{2}}
\end{aligned}
$$

The operating profits $a f(e, k, \theta)$ and $F(K, \theta)$ form the corporation tax base. The entrepreneur's dividend tax base is $d=\left(1-\tau_{c}\right) a f(e, k, \theta)+k-K$ at time $t=1$. The assets of an enterprise are sold at their net asset value at time $t=2$ and the returns are paid out as dividends.

Growth Stage: Tax Neutrality Consider then the split rule applied to dividends. The taxman imputes the income from capital at a presumptive rate of return, $\rho$, taxes $\rho B_{1}$, at the rate $\tau_{d}$ on dividends while the remaining distributed profit, $d-\rho B_{1}$, is taxed at the rate on earned income, $\tau_{w}^{i}$. Then the personal dividend taxes paid by the entrepreneur at time $t=1$ and $t=2$ are

$$
\begin{aligned}
& T_{1}^{p}=\tau_{d} \rho B_{1}+\tau_{w}^{i}\left[\left(1-\tau_{c}\right) a f(e, k, \theta)+k-K-\rho B_{1}\right] \\
& T_{2}^{p}=\tau_{d} \rho B_{2}+\tau_{w}^{i}\left[\left(1-\tau_{c}\right) F(K)+K-k-\rho B_{2}\right]
\end{aligned}
$$

making the present value of the integrated tax liability

$$
\begin{aligned}
T(e, k, K, \theta) & =\tau_{c} \frac{a f(e, k, \theta)}{1+r}+\left(\tau_{d} \frac{\rho B_{1}}{1+r}+\tau_{w}^{i} \frac{\left[\left(1-\tau_{c}\right) a f(e, k, \theta)+k-K-\rho B_{1}\right]}{1+r}\right) \\
& +\tau_{c} \frac{F(K, \theta)}{(1+r)^{2}}+\left(\tau_{d} \frac{\rho B_{2}}{(1+r)^{2}}+\tau_{w}^{i} \frac{\left[\left(1-\tau_{c}\right) F(K)+K-k-\rho B_{2}\right]}{(1+r)^{2}}\right) .
\end{aligned}
$$

It is assumed that the taxman allows $k$ to be deductible in the second period. ${ }^{16}$ Inserting the tax liability in the valuation expression, we can analyze

\footnotetext{
${ }^{16}$ This is one of the many features which makes the enterprise taxation differ from a taxation of a widely-held corporation which continues its life regardess of changes in ownership. This
} 
the issue of tax neutrality.

Using the value function in the second stage is, the first-order condition in respect of $K$ is

$$
F_{K}=\widetilde{r}-\frac{\left(\tau_{w}^{i}-\tau_{d}\right) \rho B_{2}^{\prime}}{\left(1-\tau_{c}\right)\left(1-\tau_{w}^{i}\right)}
$$

It appears that for investment neutrality in the expansion stage, the Nordic dual should make $B_{2}$ unrelated to the capital $K$, making $\rho B_{2}^{\prime}=0$. This gives $F_{K}=\widetilde{r}$ which is the conditions in a tax-free economy. Interesting enough, Sweden has adopted a system where $B_{2}=B_{2}(k)$ with no adjustment for the expansion investment $K$. Moreover, though Sweden has maintained the classical double taxation, no investment distortion need to arise in the expansion stage. This follows from two effects, the Johansson-Samuelson tax $\left(\tau_{p}=\tau_{c}\right)$ and the capitalization of the dividend tax. ${ }^{17}$ We notice that Lindhe, Södersten and Öberg (2004) were able to obtain organizational neutrality between the behavior of a $\mathrm{CHC}$ and a WHC, but the investment neutrality was not possible to obtain.

In the case of the Finnish capital base with $B=K$, enterprise taxation appears to have clear-cut effects on the expansion stage, discriminating between high-and low-profitable companies due to their the tax rate differential $\tau_{w}^{i}-\tau_{d}$ :

Proposition 5 The Nordic dual, encourages the enterprise growth for those enterprises which turned out to pass the initial stage with a high profitability. The Nordic dual punishes the expansion of those enterprises which turned out to be less profitable.

CHC: Initial Investment We focus on the case where the entrepreneur knows that the tax authority allows him to deduct the first-stage investment cost from the tax base in the second period, as it cannot represent income.

\footnotetext{
has bearing on the first-stage results.

${ }^{17}$ We find out in the next section, however, that the double taxation is not neutral with respect to market entry.
} 
Solving again for the first-order condition

$\Sigma_{i} \pi^{i}\left(1-\tau_{c}\right)\left(1-\tau_{w}^{i}\right) a f^{\prime}(k)=\widetilde{r}\left(1-\tau_{p}\right)+1-\Sigma_{i} \pi^{i}-\Sigma_{i} \pi^{i}\left(\tau_{w}^{i}-\tau_{d}\right) \rho B_{1}^{\prime}-\frac{r \Sigma_{i} \pi^{i} \tau_{w}^{i}}{1+r}$.

Again in a tax-free economy, $\Sigma_{i} \pi^{i} a f_{k}^{\prime}\left(e, k ; \theta^{i}\right)=\widetilde{r}+1-\Sigma_{i} \pi^{i}$. Solving, for the neutrality condition

$$
\rho B_{1}^{\prime}=\frac{\Sigma_{i} \pi^{i}\left[1-\left(1-\tau_{c}\right)\left(1-\tau_{w}^{i}\right)\right] a f_{k}^{\prime}\left(e, k ; \theta^{i}\right)-\widetilde{r} \tau_{p}+\frac{r \Sigma_{i} \pi^{i} \tau_{w}^{i}}{1+r}}{\Sigma_{i} \pi^{i}\left(\tau_{w}^{i}-\tau_{d}\right)}
$$

Our earlier impression repeats itself here: it is hard to obtain neutrality within the Nordic dual taxation in the initial stage. We notice that in the case of closely-held companies, it is not possible to have a simple neutrality condition because the tax rates $\tau_{w}$ vary across individuals. Though this conclusion is somewhat pessimistic for those aiming at tax neutrality, we can see from the first-order condition that the actual Nordic dual has predictable implications for the investment behavior of the CHC's.

Proposition 6 The Nordic split rule encourages the start-up investment of entrepreneurs expecting to be profitable facing a tax rate $\tau_{w}^{H}>\tau_{p}$ and discourages the investment of entrepreneurs expecting to run less profitable enterprises, facing the tax rate $\tau_{w}^{L}<\tau_{p}$.

Effects of Uncertainty We are, however, able to qualify the neutrality result when working with the success/failure but abstracting from the differences in the expected profitability. In the presence of the failure risk, the neutrality condition for the Nordic dual with respect to the early investment $k$ in CHC's simplifies to

$\rho B_{1}^{\prime}=\widetilde{r} \frac{\left(1-\tau_{p}\right)-\left(1-\tau_{c}\right)\left(1-\tau_{w}\right)}{\pi\left(\tau_{w}-\tau_{d}\right)}+\frac{\left[1-\left(1-\tau_{c}\right)\left(1-\tau_{w}\right)\right](1-\pi)+\frac{r \Sigma_{i} \pi^{i} \tau_{w}^{i}}{1+r}}{\pi\left(\tau_{w}-\tau_{d}\right)}$. 
Regardless of the complications, the risk of failure has a predictable effect: for neutrality, the failure risk enhances the required marginal capital base. One can somewhat simplify this result in the case where the elimination of the double taxation is feasible. Then, $\tau_{c}\left(1-\tau_{w}\right)=0$ and the conditions reads

$$
\rho B_{1}^{\prime}(k)=\frac{\widetilde{r}}{\pi}+\frac{\tau_{w}}{\left(\tau_{w}-\tau_{p}\right)}\left(\frac{(1-\pi)}{\pi}+\frac{\widetilde{r}\left(1-\tau_{p}\right)}{\pi\left(1+\widetilde{r}\left(1-\tau_{p}\right)\right)}\right) .
$$

\section{Career Choice: Entrepreneur or Laborer?}

It is a property of the Johansson-Samuelson tax with full loss offsets that the tax structure is neutral in respect of the career choice between the outside option and operating as a sole proprietor (i.e. an unincorporated enterprise). There is no tax issue involved. Yet most of the small enterprises operate in an incorporated form. We show that the reasons must be other than taxation, like access to limited liability and other net benefits. We argue that taxation need not be neutral in respect of the formation of incorporated companies, as CHC's. We examine the entry threshold for the CHC's in general and, thereafter, within the Nordic dual.

When incorporated, the entrepreneur maximizes

$$
V^{\tau}=\max _{e, k, K}\left[V_{o}\left(e^{\tau}, k^{\tau}, K^{\tau}\right)-\sum_{i} \pi^{i} T\left(e^{\tau}, k^{\tau}, K^{\tau}\right)\right],
$$

where the notation with the super index $\tau$ denotes the variables under taxation. Consider first the entrepreneurial choices under a uniform structure of tax rates, $\tau_{c}=\tau_{d}=\tau_{p}=\tau_{w}$. We can invoke the neutrality properties of the JohanssonSamuelson tax. Yet, the occupational choice may de distorted even with the Johansson-Samuelson tax. The reason is simple enough: in the classical tax system with no imputation, the after-tax enterprise value is lower than the 
present value of the after-tax outside option with identical cash flows. Though this mechanism is implicitly discussed in the tax literature (Harberger (1962)), the earlier work on enterprise taxation has largely abstracted from the question of occupational choice. We can show formally the following ${ }^{18}$. Let $a^{\tau}$ denote the marginal talent of an incorporated entrepreneur under taxation. Consider the case of income taxation with full loss offsets and double taxation on income from corporation. Then it follows that under a tax structure with uniform tax rates, i.e. $\tau=\tau_{c}=\tau_{d}=\tau_{w}=\tau_{p}$, there is a positive relationship between the tax rate and the marginal entrepreneurial talent, $\partial a^{\tau} / \partial \tau>0$. This result holds strictly for a tax structure which is neutral in the traditional sense that it does not distort the effort choice $e^{\tau}$ and investments $k^{\tau}, K^{\tau}$. However, we expect it to hold more generally. We therefore prove

Proposition 7 Let $a^{m}$ and $a^{\tau}$ denote the marginal entrepreneurial talents in the absence of taxation and under taxation, respectively. Then it follows that under a tax structure with uniform tax rates, i.e. $\tau=\tau_{c}=\tau_{d}=\tau_{w}=\tau_{p}$, there is a linear dependence between the marginal entrepreneurial talents

$$
a^{\tau}=\beta_{o}+\beta_{1} a^{m},
$$

where $\beta_{1}$ is a strictly positive constant and greater than one.

Proof. Available in the Technical Appendix.

The proposition suggests that even a uniform tax structure $\tau_{p}=\tau_{c}=\tau_{d}=$ $\tau_{w}$ is distortive in respect of enterprise formation. With identical cash flows, the after-tax enterprise value would be lower in the classical tax system than the present value of the after-tax outside option. The dividend tax, unless an imputation is introduced, is distortionary and affects the career choice of

\footnotetext{
${ }^{18}$ The proof is available in the Technical Appendix.
} 
individuals. For the equality $V_{o}^{\tau}\left(a^{m}\right)=w\left(1-\tau_{w}\right)$ to hold, $a^{m}$ must be greater with a uniform tax structure than in the absence of taxation, i.e. the new business idea must show greater profitability. With a non-uniform tax structure, an additional distortion may be created by the undervaluation at exit. Dividend taxation may thus have larger distortions on enterprise formation than has been previously recognized by the literature emphasizing its capitalization.

We next examine the effects of Nordic dual on entrepreneurship. Take the Finnish case for the tax-adjusted value of the enterprise. We prove the following proposition, which also holds for the Swedish and Norwegian model.

Proposition 8 The Nordic dual model encourages the establishment of new enterprises by optimistic entrepreneurs who expect with certainty $\left(\pi^{H}=1\right)$ to be of the high-profitability type. It discourages the establishment of new enterprises by entrepreneurs who expect with certainty $\left(\pi^{L}=1\right)$ to be of the low-profitability type.

Proof. Plug (17) into (16) and that into (9) to obtain $V_{o}^{\tau}\left(a^{\tau}\right)$, the taxadjusted value of an enterprise.Introduce it into the indifference condition, $Y=$ $V_{o}^{\tau}\left(a^{\tau}\right)-w\left(1-\tau_{w}\right)=0$, totally differentiate it, arriving at

$$
\frac{d a^{\tau}}{d \rho}=-\frac{\partial Y / \partial \rho}{\partial Y / \partial a^{\tau}},
$$

where

$$
\begin{aligned}
\partial Y / \partial \rho & =\frac{1}{1+r}\left(\tau_{w}^{i}-\tau_{d}\right)\left[B_{1}+\frac{B_{2}}{1+r}\right] \\
\partial Y / \partial a^{\tau} & =\frac{1}{1+r}\left(1-\tau_{w}^{i}\right)\left(1-\tau_{c}\right) f\left(e, k ; \theta^{i}\right)>0,
\end{aligned}
$$

$i=H, L$. Therefore, $d a^{\tau} / d \rho<0$, when $\left(\tau_{w}^{i}-\tau_{d}\right)>0$ and $d a^{\tau} / d \rho>0$, when $\left(\tau_{w}^{i}-\tau_{d}\right)<0$. 
Recently, Coelho, De Meza and Reyniers (2004) have suggested that entrepreneurs are typically overly optimistic. If correct, this proposal has implications when reading our results. The above proposition is informative on the effects of changing presumptive rate but given the degree of optimism or pessimism of the entrepreneur. The neutrality condition with respect to the Nordic dual

requires $\left(\frac{d a^{\tau}}{d \rho}\right)=-\frac{\partial Y / \partial \rho}{\partial Y / \partial a^{\tau}}=0$. However, this is not satisfied apart from the case $\tau_{w}^{i}-\tau_{d}$ when the Nordic dual is not needed. When high profitability enterprises are concerned with $\tau_{w}^{i}-\tau_{d}>0$, the Nordic dual encourages their entry as an increase in the presumptive rate $\rho$ reduces both the marginal and the average tax rate of high-profitability enterprises, creating the incentive suggested by our proposition. When $\tau_{w}^{i}-\tau_{d}<0$, enterprise formation is discouraged. To clarify the mechanism, we notice that with given tax rates, $\tau_{w}^{H}, \tau_{w}^{L}, \tau_{d}$, an increase in the presumptive rate $\rho$ reduces both the marginal and the average tax rate of high-profitability enterprises, creating the incentive suggested by our proposition.

\section{Concluding Discussion}

In dual income taxation a split rule is needed for closely-held companies and sole proprietors to divide business income into income from capital and labor income. Its purpose is twofold i.e. avoiding overtaxing the return on capital in unincorporated enterprises and to prevent the entrepreneurs organized as CHS's from shifting their labor income to the sphere of income from capital. This paper has studied the incentives created by such a split. We have emphasized the need to incorporate the neglected observation, the differential treatment of low and high profitability enterprises into the theory of enterprise taxation. The rules may in fact raise the tax burden of low-profitability small enterprises. These entrepreneurs face a higher cost of capital for start-up and expansion investments and 
a higher tax cost on effort provision than without the dual rules. The opposite incentives are offered to high-profitability enterprises. Their distributed profits would be taxed residually as earned income at a higher rate than the tax rate on capital income. By refraining from distributing such residual dividends and instead by investing and expanding their asset base, the basis of imputed future capital income, the entrepreneurs can smooth their tax payments. ${ }^{19}$

In our paper, we abstract from the outside financing for several reasons. Introducing outside finance would raise pertinent issue arising from informational asymmetries between the entrepreneurs and the financiers. We point to Fuest, Huber and Nielssen (2002) paper for discussion of those issues in the case of debt finance and to Keuschnigg and Nielsen (2002) in the case of venture capital finance. The earlier results by Kari (1999) and Lindhe, Södersten and Öberg (2004) point to the view that the introduction of debt financing does not raise behavioral incentives which would be particularly relevant for the dual tax.

As regards a comprehensive income tax with full offsetting of losses, which is neutral in respect of the career choice between an entrepreneur or a laborer, we show that a tax rate increase in a system with a uniform rate structure over all kinds of income can increase the ability threshold of individuals who choose entrepreneurship. With such a rate structure, the effects of the dual rules themselves vanish by definition. A general tax rate cut within uniform tax rates thus induces a larger proportion of individuals to choose entrepreneurship. But, with non-uniform personal tax rates, the Nordic dual, with its embedded split rule, tends to lower (raise) the ability threshold of entrepreneurs who expect high (low) profitability from their enterprises. Therefore, we conclude that the Nordic dual enhances entrepreneurship where high profitability is expected.

\footnotetext{
${ }^{19}$ The dual rules prevent the entrepreneur from avoiding the high marginal tax rate on earned income at exit by either double-taxing undistributed profits (Finland), taxing only windfall capital gains (Norway) or by applying the split rule to realized capital gains (Sweden).
} 


\section{Technical Appendix to "Nordic Dual Income Taxation of Entrepreneurs"}

\subsection{Proof of the Career Choice}

Plug the expression of tax liability (18) into the maximand (9) to derive the tax-adjusted value of the enterprise. We then prove the result that under a tax structure with uniform tax rates, i.e. $\tau=\tau_{c}=\tau_{d}=\tau_{w}=\tau_{p}$, there is a positive relationship between the tax rate and the marginal entrepreneurial talent, $\partial a^{\tau} / \partial \tau>0$, where the tax structure is constructed to be neutral in respect of effort choice $e^{\tau}$ and investments $k^{\tau}, K^{\tau}$. We assume that there is perfect loss-offset even for a start-up firm. Disallowing for perfect loss-offset would make our result hold for a further reason.

Consider thus the indifference (identity) condition for occupational choice under taxation, i.e. an entrepreneur versus a laborer,

$$
V_{o}^{\tau}\left(a^{\tau}\right)=w\left(1-\tau_{w}\right)
$$

or

$$
\begin{aligned}
& -\left(c\left(e^{\tau}\right)+k^{\tau}\right)+\pi \frac{1}{1+\widehat{r}\left(1-\tau_{p}\right)}\left[a^{\tau} f\left(e^{\tau}, k^{\tau}\right)+k^{\tau}+V_{1}^{* \tau}(\theta)\right] \\
& -\pi\left[\tau_{c} \frac{a^{\tau} f\left(e^{\tau}, k^{\tau}\right)}{1+\widehat{r}\left(1-\tau_{p}\right)}+\tau_{d} \frac{\left(1-\tau_{c}\right) a^{\tau} f\left(e^{\tau}, k^{\tau}\right)+k^{\tau}-K^{\tau}}{1+\widehat{r}\left(1-\tau_{p}\right)}\right] \\
& -\pi\left[\tau_{c} \frac{F\left(K^{\tau}\right)}{\left(1+\widehat{r}\left(1-\tau_{p}\right)\right)^{2}}+\tau_{d} \frac{\left(F\left(K^{\tau}\right)\left(1-\tau_{c}\right)+K^{\tau}\right)-k^{\tau}}{\left(1+\widehat{r}\left(1-\tau_{p}\right)\right)^{2}}\right] \\
& -w\left(\tau_{p}\right)\left(1-\tau_{w}\right)=0 .
\end{aligned}
$$

Derive then the impact of an increase in the tax rate on the ability of the marginal entrepreneur. There will be three mechanisms to be considered. First, a 
marginal increase in tax rates reduces the after-tax cash flows to the enterprise in both production periods. This tends to raise the entrepreneurial threshold. However, there is an offsetting effect to the extent that the discount rate decreases. This effect will tend to push up the discounted value of the after-tax cash flows, though they are reduced in size. Third, an increased tax on interest income raises the present value of wage income in labor contracts. This is also bad news for entrepreneurship because it tends to push up the entrepreneurial threshold as labor market prospects are more attractive than they used to be. The present value of labor income, written explicitly, is

$$
w\left(\tau_{p}\right)=w_{o}\left[\frac{1}{1+\widehat{r}\left(1-\tau_{p}\right)}+\left(\frac{1}{1+\widehat{r}\left(1-\tau_{p}\right)}\right)^{2}\right]
$$

and we recall,

$$
V_{1}^{* \tau}(\theta)=-K+\frac{F\left(K^{\tau}\right)+K^{\tau}}{1+\widehat{r}\left(1-\tau_{p}\right)} .
$$

Inserting, we obtain

$$
\begin{aligned}
& -\left(c\left(e^{\tau}\right)+k^{\tau}\right)+ \\
& \pi \frac{1}{1+\widehat{r}\left(1-\tau_{p}\right)}\left[\left(1-\tau_{d}\right)\left(1-\tau_{c}\right) a f\left(e^{\tau}, k^{\tau}\right)-\left(1-\tau_{d}\right) K^{\tau}+\left(1-\tau_{d}\right) k^{\tau}\right]+ \\
& \pi\left(\frac{1}{1+\widehat{r}\left(1-\tau_{p}\right)}\right)^{2}\left[\left(1-\tau_{d}\right)\left(1-\tau_{c}\right) F\left(K^{\tau}\right)+\left(1-\tau_{d}\right) K^{\tau}+\tau_{d} k^{\tau}\right] \\
& =\left(1-\tau_{w}\right) w\left(\tau_{p}\right) .
\end{aligned}
$$

Totally differentiating with respect to $\tau$ and $a^{\tau}$, the entrepreneurial threshold 
is determined as

$$
\begin{aligned}
\frac{d a^{\tau}}{d \tau} & =\frac{1}{(1-\tau)(2+r) f\left(e^{\tau}, k^{\tau}\right)}\left[\frac{2 F\left(K^{\tau}\right)+a f\left(e^{\tau}, k^{\tau}\right)\left(r^{2}+4 r+2\right)}{1+r}+\right. \\
& \frac{\left.2\left(c\left(e^{\tau}\right)+k^{\tau}\right)\right)}{\pi(1-\tau)^{2}}- \\
& \left.\frac{2(1-\tau) r K^{\tau}+2(1-(1-\tau) r) k^{\tau}}{(1-\tau)^{2}(1+r) .}\right] .
\end{aligned}
$$

The entrepreneurial threshold is distorted by taxation even at uniform rates, basically because entrepreneurial income is subject to double taxation in an incorporated enterprise. This is the effect hinted at by King (1989). The ability threshold of the marginal entrepreneur is increased if $\frac{d a^{\tau}}{d \tau}>0$. The expression for $\frac{d a^{\tau}}{d \tau}$ can be grouped into two positive terms and one negative term. Recall that the opportunity cost $r$ can be thought of as a compound return over a number of years and the operating cash flows are similarly accumulated returns over each stage. Therefore, the positive terms outweigh the negative term.

\subsection{Proof of Proposition 7.}

In the absence of taxation, the marginal entrepreneur $a^{m}$ is identified from the condition $-(c(e)+k)+\pi \frac{1}{1+r}\left[a^{m} f(e, k)+k+V_{1}^{*}(\theta)\right]=w$. Inserting into the indifference condition under taxation, and recalling that $V_{1}^{*}(\theta)=-K+\frac{F(K)+K}{1+r(1-\tau)}$, we find that there is a linear dependence between the marginal abilities

$$
a^{\tau}=\beta_{o}+\beta_{1} a^{m} .
$$

Its parameters are given by

$$
\beta_{1}=\frac{\left(1-\tau_{w}\right)}{\left(1-\tau_{c}\right)\left(1-\tau_{d}\right)} \frac{f(e, k)}{f\left(e^{\tau}, k^{\tau}\right)}
$$


and by

$$
\beta_{o}=\frac{1}{\left(1-\tau_{c}\right)\left(1-\tau_{d}\right)}\left[\frac{1}{\frac{\pi}{1+\widehat{r}(1-\tau)} f\left(e^{\tau}, k^{\tau}\right)} Z+\frac{w(\tau)-w}{1-\tau_{w}}\right]
$$

where

$$
\begin{aligned}
Z & =\left(c\left(e^{\tau}\right)+k^{\tau}\right)-\left(1-\tau_{w}\right)(c(e)+k) \\
& +\pi \frac{1}{1+\widehat{r}(1-\tau)}\left[\left(1-\tau_{w}\right) V_{1}^{*}(\theta)-V_{1}^{* \tau}(\theta)\right] \\
& +\pi \frac{1}{1+\widehat{r}(1-\tau)}\left[\left(1-\tau_{w}\right)\left(k-\left(1+\tau_{d}\right) k^{\tau}\right)\right] \\
& +\pi\left[\tau_{d} \frac{-K^{\tau}}{1+\widehat{r}(1-\tau)}+\tau_{c} \frac{F\left(K^{\tau}\right)}{(1+\widehat{r}(1-\tau))^{2}}\right. \\
& \left.+\tau_{d} \frac{\left(F\left(K^{\tau}\right)\left(1-\tau_{c}\right)+K^{\tau}\right)}{(1+\widehat{r}(1-\tau))^{2}}\right]
\end{aligned}
$$

We know that under distortive taxes, $e^{\tau}<e, k^{\tau}<k$, and that $K^{\tau}<K$. Thus, $\frac{f(e, k)}{f\left(e^{\tau}, k^{\tau}\right)}>1$. With a uniform tax rate, $\frac{\left(1-\tau_{w}\right)}{\left(1-\tau_{c}\right)\left(1-\tau_{d}\right)}>1$. Therefore, $\beta_{1}>>1$. Moreover, the greater the dividend and the corporate tax rates are, the greater the coefficient $\beta_{1}$ is. This tends to make $a^{\tau}>a^{m}$. We notice that there are both positive and negative terms in $Z$. Yet, the term $\frac{w(\tau)-w}{1-\tau_{w}}$ definitively is positive. Though we cannot determine the sign of $Z$ for sure, the facts are that $\beta_{1}>>1$ and that $\frac{w(\tau)-w}{1-\tau_{w}}>0$. This allow us to suggest that the dependence between $a^{\tau}$ and $a^{m}$ is positive; as a matter of fact, $\beta_{o} \geq 0$ is not even needed for $a^{\tau}>a^{m}$.

\section{References}

[1] Alstadsæter, A. (2003), "The Dual Income Tax and Firm's Income Shifting Through the Choice of Organizational Form and Real Capital Investments", CESifo working papers no. 1018, August 2003.

[2] Auerbach, A.J. (1979), "Wealth Maximization and the Cost of Capital", Quarterly Journal of Economics 94, 433-446.

[3] Auerbach, A.J. (1983), "Taxation, Corporate Financial Policy and the Cost of Capital", Journal of Economic Literature 21, 905-940. 
[4] Bergström, V. and Södersten, J., (1977), Double Taxation and Corporate Capital Costs, Presented at the Econometric Society Meeting, Vienna, 6-9 September, 1977.

[5] Bradford, D.F. (1981), "The Incidence and Allocation effects of a Tax on Corporate Distributions", Journal of Public Economics 15, 1-22.

[6] CESifo DICE Report, Journal of Institutional Comparisons, 2, Autumn 2004.

[7] Coelho, M., De Meza, D., and Reyniers, D. (2004), "Irrational Exuberance, Entrepreneurial Finance and Public Policy", International Tax and Public Finance 11: 391-417.

[8] De Meza, D. and D. Webb (1999), "Wealth, Enterprise and Credit Policy", The Economic Journal 109, 153-163.

[9] Domar, E.D. and R.A. Musgrave (1944), "Proportional Income Taxation and Risk-Taking", Quarterly Journal of Economics 58, 388-422.

[10] Edwards, J.S.S. and M.J. Keen (1984), "Wealth Maximization and the Cost of Capital: a Comment", Quarterly Journal of Economics 99, 211-214.

[11] Fjærly, E. and Lund, D., (2001), "The Choice Between Owner's Wage and Dividends Under the Dual Income Tax", Finnish Economic Papers 14, 104119.

[12] Fuest, C., Huber, B., and Nielsen, S.B., (2002) "Why is the corporation tax rate lower than the personal tax rate? The role of new firms", Journal of Public Economics 87,157-174.

[13] German Council of Economic Experts (2006), Reform der Einkommensund Unternehmensbesteuerung durch die Duale Einkommensteuer. Expertise im Auftrag der Bundesminister der Finanzen und für Wirtschaft und Arbeit vom 23. Februar 2005. Wiesbaden.

[14] Hagen, K.P. and P.B. Sørensen (1998), "Taxation of Income from Small Business: Taxation Principles and Tax Reforms in the Nordic Countries", in Sørensen, P.B., Tax Policy in the Nordic Countries, London: MacMillan Press Ltd.

[15] Harberger, A.C., (1962), "The incidence of the corporation income tax", Journal of Political Economy, 70, 215-240.

[16] Kari, S. (1999), Dynamic Behaviour of the Firm Under Dual Income Taxation, Government Institute for Economic Research, Research Reports 51, Helsinki.

[17] Keuschnigg, C., and Nielsen, S.B., (2002), "Tax policy, venture capital, and entrepreneurship", Journal of Public Economics 87, 175-203. 
[18] Keuschnigg, C., and Dietz, M. (2005), "A Growth-Oriented Dual Income Tax", CESifo wp. 1513.

[19] King, M.A. (1974), "Dividend Behaviour and the Theory of the Firm", Economica 41, 25-34.

[20] King, M.A.(1989), "Economic Growth and the Life-Cycle of Firms", European Economic Review 33, 325-334.

[21] Lindhe, T., J. Södersten, and A. Öberg (2002), "Economic Effects of Taxing Closed Corporations under a Dual Income Tax". Ifo Studien 48, 575-609.

[22] Lindhe, T., J. Södersten, and A. Öberg (2004), "Economic Effects of Taxing Different Organizational Forms under the Nordic Dual Income Tax", International Tax and Public Finance 11, 469-485.

[23] Nielsen, S.B. and P.B. Sørensen (1997) "On the optimality of the Nordic system of dual income taxation", Journal of Public Economics 63, 311-329.

[24] Panteghini, P. (2001), "Dual Income Taxation: The Choice of the Imputed Rate of Return", Finnish Economic Papers 14, 5-13.

[25] Sinn, H.-W. (1987), Capital Income Taxation and Resource Allocation, Amsterdam: North-Holland.

[26] Sørensen, P.B. (1994), "From the Global Income Tax to the Dual Income Tax: Recent Tax Reforms in the Nordic Countries", International Tax and Public Finance 1, 57-79.

[27] Sørensen, P.B. (2005a), Neutral taxation of shareholder income: A Norwegian tax reform proposal, International Tax and Public Finance 12, 777-801.

[28] Sørensen, P.B. (2005b), Dual Income Tax: Why and How? FinanzArchiv $61,559-586$.

[29] Tikka, K.S. (1993), "A 25 \% Flat Tax on Capital Income: The Finnish Reaction to International Tax Competition", in Tax Reform in the Nordic Countries - 1973-1993 Jubilee Publication, Nordic Council for Tax Research, Iustus Förlag, Gothenburg. 